\title{
CLIMATOLOGIA: ENSINO E EMPREGO DE GEOTECNOLOGIAS ${ }^{1}$
}

\author{
FIALHO, Edson Soares - fialho@ufv.br \\ Departamento de Geografia da Universidade Federal de Viçosa (UFV) e Laboratório de Biogeografia e Climatologia- \\ BIOCLIMA.
}

\begin{abstract}
RESUMO: O ensino de climatologia, nos dias de hoje, sofre com uma incômoda discussão, muitas vezes inerte e superficial, referente às mudanças climáticas globais. Tal comportamento verificado não apenas em sala de aula abdica de um raciocínio dialético em favor de uma perspectiva do "politicamente correto", abordado por Collischonn e Fialho (2007). Em um mundo de incertezas e avanços geotecnológicos, é muito difícil encontrar opiniões convergentes. E por isso, é de se estranhar que o tema das questões climáticas globais seja aceito sem reflexões, como se o determinismo climático imperasse novamente. $\mathrm{E}$ isto se torna mais grave em ambientes universitários de formação de professores, local fonte de disseminação de "saberes científicos", que não são "verdades absolutas" nas escolas, onde os alunos aceitam a informação de maneira inquestionável, ampliando a sensação de "certeza", corroborada pela cobertura jornalística. Nesse cenário, o presente trabalho buscará refletir sobre o clima e o tempo, temas de interesse secular, no ambiente acadêmico e escolar, para discutir neste artigo os problemas inerentes à transposição dos conhecimentos climatológicos produzidos pela academia até os bancos escolares, no intuito de reduzir o fosso entre a universidade e a escola, bem como os desafios de aperfeiçoar os métodos de ensino no meio acadêmico, que agora contam com a possibilidade de novas geotecnologias para o processo de ensino e aprendizagem.

Palavras-chave: Climatologia, Ensino e Geotecnologias.
\end{abstract} CLIMATOLOGY: EDUCATION AND GEOTECHNOLOGY APPLICATION

ABSTRACT: The teaching of climatology, nowadays, suffers from an uncomfortable discussion, often inert and superficial related to global climate changes. Such behavior not only checked in the classroom abdicates of a dialectical reasoning in favor of a perspective of "politically correct", and approached by Collischonn Fialho (2007). In a world of uncertainty and geotechnologics advances is very difficult to find convergent opinions. And therefore, is not a surprise that the theme of global climatic issues, be accepted without reflections, as if the climatic determinism reigned again. And this becomes more severe in the academic environments were the formation of teachers happen, place that is source of dissemination of "scientific knowledge" that are not "absolute truths" in schools where students accept the information without questioning, increasing the sense of "certainty "confirmated by the media coverage. In this scenario, this paper aims to reflect about the climate and weather, secular topics of interest in the academic environment and school, in order to discuss in this article the problems inherent in the translating the climatological knowledge produced by the academy to school banks, in order to reduce the gap between the university and the school, as well as the challenges of improving the teaching methods in the academic environment, which now include the possibility of new geotechnologies to the process of teaching and learning.

Keywords: Climatology, Teaching and Geotechnologies

\section{INTRODUÇÃO}

O presente artigo, além de atender ao convite para integrar a mesa redonda intitulada "Climatologia: Ensino e emprego de geotecnologias", no X SBCG, realizado no mês de novembro de 2012, na cidade de Manaus-AM, tem como objetivo principal discutir o ensino da climatologia em um mundo globalizado, em que as tecnologias, ou melhor, as geotecnologias propiciam maior velocidade no trânsito das informações bem como possibilidades advindas da utilização de tal ferramental na melhoria do ensino.

A responsabilidade de abordar tal assunto é maior, na medida em que esta temática ocupa, pela primeira vez, um lugar de destaque entre os eixos orientadores do SBCG, o que possibilita a questão de o ensino se evidenciar em um espaço de mesa. Isso com certeza é um sinal de que a produção e a preocupação com o ensino em climatologia se fazem presentes na atualidade.

Ao preparar o material para discussão, devo confessar que enfrentei algumas dificuldades quando me aproximei da área de ensino do clima, muito embora já tivesse desenvolvido carreira docente nesta área, no Ensino Fundamental e Médio da Rede Estadual de Educação

\footnotetext{
${ }^{1}$ Palestra proferida no X Simpósio Brasileiro de Climatologia Geográfica, realizado na cidade de Manaus, entre 16 e 23 de novembro de 2012.
} 
do Estado do Rio de Janeiro, entre os anos de 1998 e 2006, ano em que ingressei na Universidade Federal de Viçosa (UFV).

No I Seminário de Ensino de Geografia da UFBA (I SEG-UFBA) em 2011, apresentei minhas primeiras reflexões acerca do Ensino de Geografia, mais especificamente, a Climatologia. Esclareço ainda que, embora seja docente, meu objeto de pesquisa não é diretamente o Ensino de Geografia, mas a Climatologia, contudo, o fato de ministrar, atualmente, aulas para a Licenciatura e Bacharelado de Geografia na UFV me permite investir na investigação científica ao mesmo tempo em que estabeleço contato com o saber escolar, através dos discentes de primeiro período, que ainda têm uma grande influência do ensino médio. $E$ neste caso, percebo que os alunos recém-ingressos no mundo universitário estão cada vez mais defasados. Conteúdos que teoricamente deveriam ser abordados no Ensino fundamental e médio estão sendo relegados. A consequência de tal ausência se reflete em classe, com alunos que não conseguem acompanhar o ritmo da aula, bem como apresentam dificuldades de concentração e compreensão dos textos de leitura obrigatória da disciplina.

Em razão deste contexto, nesta obra, retomarei a algumas questões que inicialmente abordei em 2007, voltadas ao Ensino Fundamental e Médio, no trabalho intitulado "Práticas do Ensino de Climatologia através da observação sensível", que ainda são pertinentes.

A) O ensino do clima hoje é interessante para o aluno?

B) Os professores estão inteirados dos processos inerentes aos fenômenos meteorológicos?

Acredito que essas questões sejam também pertinentes quando se pensa o meio universitário, ambiente responsável pela formação de futuros professores que lecionarão Climatologia para alunos do ensino fundamental e médio, através da disciplina de Geografia, hoje revitalizada pelo uso das geotecnologias. E quando penso nesse novo ferramental que invade a sala de aula sem uma reestruturação da escola, me pergunto:

C) Será que as geotecnologias estão contribuindo para o aprimoramento e a disseminação da Climatologia na escola e na universidade?

D) A questão abordada inicialmente por Sant'anna Neto (2000) referente à distância entre o produzido e o ensinado aumentou desde 2000 no âmbito da Climatologia?

E) O maior investimento do governo nas universidades, promovendo a instituição do PIBID, já se reflete na melhoria do ensino da climatologia no nível superior e nas escolas?

A partir desse mote inicial, a estrutura do artigo será dividida em 4 partes. Primeiramente, abordaremos a questão do Ensino de Geografia, em seguida, a questão do conceito de clima e tempo e os conteúdos de climatologia nos livros didáticos. No terceiro item, o uso das geotecnologias no ensino da climatologia e, por fim, no quarto tópico, abordaremos a relação entre o que é produzido e ensinado na climatologia, bem como as perspectivas e óbices do ensino do clima.

\section{O ENSINO DE GEOGRAFIA.}

A Geografia Escolar, entre as demais disciplinas do currículo da Escola, é a encarregada de tentar explicar o mundo aos jovens estudantes. A princípio, isso é um grande desafio, entretanto, a compreensão dos alunos acerca da Geografia como disciplina escolar é de que ela não é tão significante, na medida em que se acredita que o ato de ler um jornal ou revista sobre atualidades bastaria para estudar Geografia. Isto porque em parte ainda persiste a utilização de métodos de memorização, entendida na linguagem estudantil, como decoreba.

Porém, tal visão por parte do aluno deve ser superada pela mediação do professor, pois a educação, que acontece, atualmente, em um mundo globalizado, deve superar a transmissão dos conhecimentos que existem e ensinar a pensar, a buscar e a construir.

Fato esse corroborado por Bertrand e Bertrand (2007) ao afirmar que a Geografia não pode pretender como ela o fez ao longo dos séculos passados e ainda na maior parte de nossos manuais de ensino, transmitir a totalidade do fato natural, sob todos os aspectos e em todas as escalas de tempo e espaço. Isto porque, corre-se o risco de se fazer uma compilação de 
informações veiculadas pela mídia e outras ciências e, por consequência, ocultar o que realmente é fruto da pesquisa na área de Geografia.

Todavia, segundo Callai (2007, p. 4), a Escola, que se depara cada vez mais com acúmulo de funções delegadas pelas famílias e pela sociedade, é impedida de fazer sua especificidade. Exemplo disso está no bojo da proposição de trabalhar com as competências, que são as proposições de como o jovem deve agir, de como deve se preparar e do como se insere no mundo, que assumem lugar significativo nos currículos escolares.

Nesse conflito entre o que a Escola deve ensinar e as funções que ela adquiriu, mesmo sem querer ela promoveu o distanciamento, conforme atesta Cassab (2009, p. 49), entre a Geografia produzida na universidade e a ensinada na Escola, apresentando grande abismo.

Em um contexto brasileiro há avanços institucionais, apesar das diferentes orientações e conteúdos recentes e muitas destas através do Plano Nacional Curricular $\left(\mathrm{PCN}^{2}\right)$. Este descompasso possibilita a perpetuação de uma Geografia clássica descritiva, que ainda acompanha o ensino da disciplina, influenciando a forma de se ensinar e aprender Geografia até os dias de hoje, que retroalimenta o mito por parte dos discentes de que a disciplina apenas transmite informações jornalísticas bem como de uma Escola conteudísta.

Em pesquisas comparativas realizadas por Charlot (2001 apud VERHAEGHE, 2010, p. 116) entre alunos franceses e brasileiros, os jovens provenientes de meios desfavorecidos mostram que as aprendizagens que esses jovens julgam mais importantes ou significativas são aquelas que dizem respeito à esfera relacional por eles adquiridas em boa parte no meio familiar e em seu círculo imediato.

Os saberes escolares e disciplinares, suscetíveis, portanto de fornecer modelos de inteligibilidade sobre o mundo, são pouco citados. Pode-se formular a hipótese de que os saberes escolares Ihes parecem amplamente desconectados das questões éticas, sociais, mas também epistemológicas que poderiam Ihes dar sentido. Com efeito, que sentido esses alunos atribuem ao aprendizado escolar? Na pesquisa de Charlot (1992, apud VERHAEGHE, 2010, p. 116 e 117), constata-se que, para uma parte dos alunos:

\begin{abstract}
"...aprender não é adquirir saberes que apresentam por si mesmo um interesse próprio, um valor, sentido. Para esses alunos, o saber não é nem objetivado nem sistematizado em um universo intelectual. Aprender é satisfazer as exigências da escola para ter acesso à série seguinte, à universidade, ao diploma, ao bom emprego etc. Aprender é fazer matemática, francês, história e geografia; as disciplinas escolares não sendo então percebidas como conjuntos coerentes de saberes, mas sim como formas institucionais de recorte do tempo escolar. O saber é então percebido como algo não operacional, as diferentes matérias ensinadas são percebidas como uma e realidade etérea que não permite senão a constituição de um programa de estudos...".
\end{abstract}

Além disso, a escola também dificulta o processo de aprendizagem, pois ao se deter no processo de didatização, que visa a apresentar o saber de forma mais acessível, ela tende a decompor o saber em unidades menores, seguindo a vontade de garantir certa progressividade das aprendizagens.

Os modelos explicativos construídos pelos alunos ou aos quais ele faz referência para explicar um fenômeno geralmente são simples, em ligação direta com sua vivência. Além disso, eles, muito frequentemente, são organizados de maneira lógica, coerente (mesmo que sejam falsos). É esse caráter organizado e estruturado que os tornam resistentes.

Nesse ambiente, o professor, segundo Gebran (2003, p. 82), deve assumir o seu papel na construção de conhecimentos, possibilitando a análise do espaço numa visão dialética que

\footnotetext{
2 Os Parâmetros Curriculares Nacionais (PCNs) são referenciais de qualidade elaboradas pelo Governo Federal em 1996. Essas diretrizes são voltadas, sobretudo, para a estruturação e reestruturação dos currículos escolares de todo o Brasil - obrigatórias para a rede pública e opcionais para as instituições privadas. Ou seja, o objetivo principal dos PCN é padronizar o ensino no país, estabelecendo pilares fundamentais para guiar a educação formal e a própria relação escola-sociedade no cotidiano. Divididos em disciplinas, os parâmetros abrangem práticas de organização de conteúdo, formas de abordagem das matérias com os alunos, a aplicação prática das lições ensinadas e a melhor conduta a ser adotada pelos educadores em situações diversas.
} 
favorecerá a proposição de situações e atividades, no decorrer do processo educativo, capazes de permitir ao aluno realizar a tarefa de entender a Geografia como ciência que investiga e pesquisa o espaço, buscando suas múltiplas relações, suas contradições e concebendo-a em contínua transformação, dada pelo próprio movimento da sociedade. Assim, reconstruindo as lógicas ou modelos de compreensão de mundo dos alunos, que são constantemente refeitos. Essa proposta encaminha para necessidade da apropriação e produção do conhecimento geográfico pelo aluno, de modo compreender as relações socioculturais e a dinâmica dos processos físicos e naturais, contextualizados historicamente, utilizando-se de uma forma singular de conhecer e desvelar a realidade: o conhecimento geográfico.

Tais atividades envolvem articulação e entrelaçamentos com outras áreas do conhecimento e a definição de noções básicas ligadas às questões de espaço e tempo, encaminhando para o desenvolvimento de uma postura crítica, reflexiva e interpretativa da sua realidade social. Mas de maneira geral, Verhaeghe et al. (2010) propõem como solução para o ensino na Escola o exercício da Prática da Epistemologia, ou seja, iniciar os alunos em uma reflexão epistemológica através de quatro pontos: A) Enfatizar o caráter construído e humano dos saberes ensinados; B) Problematizar o saber; C) Favorecer um aprendizado de tipo construtivista; e D) Suscitar uma reflexão sobre a dimensão ética dos saberes.

No fim deste item, lanço uma questão ligada ao pensamento da reformulação da matriz curricular, com base na proposta de Verhaeghe et al. (2010), que, embora não tenha me detido em uma maior reflexão mais apurada, me preocupa, principalmente, quando órgãos governamentais, como o Ministério da Educação (MEC), ventilam a possibilidade de mudança da estrutura curricular, por meio de veículos de comunicação, após resultados institucionais insatisfatórios das escolas públicas e privadas, como, por exemplo, a matéria retratada na reportagem de Takahashi (2012), publicada no jornal Folha de São Paulo, que relata o desejo do MEC de alterar a organização das disciplinas nas escolas sem uma discussão mais detida com os profissionais envolvidos no processo de aprendizagem.

A mudança prevê uma reorganização no quadro da grade, que atualmente apresenta 13 disciplinas para um cenário de apenas 4 áreas (ciências humanas, ciências da natureza, linguagens e matemática). Tal alteração apenas enquadra o Ensino Médio de acordo com o processo avaliativo do Enem, que já segue esse formato. Será que apenas isso resolverá os problemas de rendimento da Escola sem um conjunto de medidas paralelas que possam potencializar resultados concretos a curto e médio prazo?

\section{A CLIMATOlogia e O CONCEITO DE TEMPO E CLIMA NOS LIVROS DidÁticos.}

O livro didático vem sendo objeto de estudo de inúmeros trabalhos que o conceituam como um instrumento mal elaborado por não atender aos interesses da comunidade escolar. Porém esse mesmo material, ao contrário do que muitos pensam, não pode ser a única orientação. Nesse sentido, a escola e o professor devem utilizar outras linguagens como: a literatura (MEDEIROS; HOLANDA, 2008), o cinema (CAMPOS, 2006), o trabalho de campo (FIALHO, 2002 e 2007a), a teatralização, seminários, entre outras formas, a fim de não abdicar do raciocínio dialético em favor da perspectiva do "politicamente correto", que considera a única forma admissível de abordagem (COLLISCHONN; FIALHO, 2007).

Porém, em razão dos problemas contingenciais, o professor, embora conheça essas possibilidades, não está valorizado e estimulado, na atual conjuntura, a aplicar outros métodos de ensino e ainda está preso por exigência dos pais ao mito do bom professor (FIALHO, 2008), que vincula a competência do profissional de educação à sua capacidade de vencer o conteúdo.

E não é raro acontecer de o professor lecionar para si mesmo, uma vez que o aluno detentor de conhecimentos fragmentados termina não entendendo, pois ainda não tem a capacidade de relacionar os conteúdos entre si. Por causa disso, acaba lançando mão da decoreba e assim que possível a descarta.

Nesse contexto, o livro didático deixa de ser o instrumento e passa a ser o comandante do processo pedagógico. A consequência disso é o sucateamento intelectual nas escolas e o aumento da distância entre o conhecimento produzido nas universidades e o contido nos livros didáticos, agravado pela falta da pesquisa e reflexão na escola. Esse fato somente reforça a ideia de que a universidade é o único centro de produção do conhecimento. E enquanto esse pensamento prevalecer, os conflitos inerentes à relação escola/universidade continuarão ad infinitum. 
A busca por valorizar o saber construído pelo aluno para trabalhar com a noção de percepção para exercitar a observação do ritmo da atmosfera e sua repercussão sobre o espaço contribui no processo de ensino e aprendizagem.

O estudo do clima através da percepção não se restringe ao meio escolar, podendo ser aplicado nos cursos de formação de professores, que, ao longo da graduação, podem não ter tido a oportunidade de experimentar práticas pedagógicas diferentes da aula expositiva. Nesse sentido, a experiência de registro de elementos do clima por meio de equipamentos alternativos ou simplesmente da observação do tempo pode:

"...dar ao aluno-professor mais segurança na realização de trabalhos práticos com seus alunos, podendo assim valorizar a percepção que os alunos têm do seu dia a dia..." (CASTRO, 1997).

Nesse contexto, se o estudo do clima na Escola deve instigar o aluno a acompanhar as mudanças de tempo em seu cotidiano, através dos registros dos elementos do clima, então, o que é o clima e o tempo? Embora possa parecer uma questão sem propósito, ao realizarmos um levantamento de conceitos a respeito do clima, Tabela 1, constatamos uma grande diversidade, porém com algum esforço podem ser encontradas certas características comuns, agrupadas em duas linhas de pensamento distintas.

Uma compreende o clima como o estado médio e a outra, como uma sucessão habitual da atmosfera. Tais abordagens, apesar de distintas, Barros e Zavatini (2009, p. 260), em relação às duas abordagens, concluem que uma complementa a outra, e que vislumbrar e compreender o verdadeiro quadro climático significa, também, saber equilibrá-las nas investigações a que se propõe realizar.

Como identificado, na academia existem duas linhas de pensamento a respeito do clima, que em certa medida são traspostas ao meio escolar, muitas vezes sem uma preocupação criteriosa de elucidar. Fialho (2007a), em seu levantamento realizado, Tabela 2, procurou analisar o conceito de clima através de três paradigmas (Tradicional, Dinâmico e Misto), tendo verificado que o dinâmico e o misto, ambos apresentaram $36,3 \%$ de participação contra $27,4 \%$ do tradicional, em uma amostra de 11 títulos.

Tabela 1. Definições do conceito de Clima.

\begin{tabular}{|c|c|}
\hline Autores & Definição \\
\hline Köppen(1906) & $\begin{array}{l}\text { Clima é o estado médio e o processo ordinário do tempo em um lugar } \\
\text { determinado, tendo em conta que o tempo muda, porém o clima se mantém } \\
\text { constante. }\end{array}$ \\
\hline Ward (1914) & $\begin{array}{l}\text { Ë a totalidade do tempo meteorológico; os totais climáticos são os resultados } \\
\text { dos totais do tempo metereológicos durante muitos anos. }\end{array}$ \\
\hline Sekic & $\begin{array}{l}\text { As condições climáticas que contemplam uma determinada localidade com uma } \\
\text { variabilidade. }\end{array}$ \\
\hline Drosdow (1956) & A média de muitos anos de situações de tempo características. \\
\hline OMM & $\begin{array}{l}\text { O conjunto flutuante das condições atmosféricas, caracterizado pelos estados e } \\
\text { evolução do tempo no curso de um período suficientemente longo, em um } \\
\text { domínio espacial determinado. }\end{array}$ \\
\hline Sor & $\begin{array}{l}\text { O clima é um ambiente atmosférico constituído pela série de estados da } \\
\text { atmosfera, em determinado lugar, em sua sucessão habitual, fazendo } \\
\text { referência à climatologia dinâmica. }\end{array}$ \\
\hline Blair ( & $\begin{array}{l}\text { totalidade das condições de tempo num dado período de tempo, incluindo } \\
\text { ambém os extremos e a variabilidade dos elementos do tempo. }\end{array}$ \\
\hline $\begin{array}{r}\text { Péd } \\
\text { (1 }\end{array}$ & $\begin{array}{l}\text { Um conjunto de tendências estáveis que resultam das condições permanentes } \\
\text { durante um período de } 30 \text { anos. }\end{array}$ \\
\hline Monte & $\begin{array}{l}\text { Ë comportamento dinâmico mais habitual dos tipos de tempo ou recorrente da } \\
\text { atmosfera sobre um dado lugar. }\end{array}$ \\
\hline Pagney & $\begin{array}{l}\text { O estado da atmosfera que se traduz de modo original tendo em conta a } \\
\text { posição da latitude do lugar considerado e a natureza do substrato (continente } \\
\text { ou oceano). }\end{array}$ \\
\hline Strang (1980) & $\begin{array}{l}\text { Variabilidade média dos elementos do tempo, durante um período } \\
\text { relativamente longo. }\end{array}$ \\
\hline & npo atmosférico médio. \\
\hline Ayoade (1983) & po em um de \\
\hline
\end{tabular}




\begin{tabular}{|c|c|}
\hline Goudie (1985) & $\begin{array}{l}\text { ão as características atmosféricas que normalmente são representadas por } \\
\text { neio de dados numéricos dos elementos metereológicos, tais como } \\
\text { emperatura, pressão, vento, precipitação e umidade. }\end{array}$ \\
\hline Lockv & ão sistemas e seus tipos de tempo. \\
\hline $\mathbf{G}$ & $\begin{array}{l}\text { probabilidade estatística de ocorrência de distintos estados da atmosfera } \\
\text { obre uma localidade ou região, durante um tempo cronológico determinado. }\end{array}$ \\
\hline & clima é uma certa regularidade subjacente a uma aparente desordem. \\
\hline Bar & $\begin{array}{l}\text { Para conhecer o clima de um lugar ou de uma região é necessário dispormos } \\
\text { de uma longa série de observações ( } 20 \text { ou } 30 \text { anos) de modo que precisas } \\
\text { informações das mais frequentes condições e duas variações estejam } \\
\text { disponíveis. }\end{array}$ \\
\hline ) & $\begin{array}{l}\text { É o resultado de um processo complexo envolvendo atmosfera, oceano, } \\
\text { superfícies sólidas (vegetadas ou não), neve, gelo, apresentando enorme } \\
\text { variabilidade no espaço e no tempo. }\end{array}$ \\
\hline Viane & $\begin{array}{l}\text { O Clima é a generalização ou a integração das condições do tempo para um } \\
\text { certo período, em uma determinada área. }\end{array}$ \\
\hline 1) & $\begin{array}{l}\text { O clima de um lugar pode ser considerado como a integração de uma série de } \\
\text { elementos que se verificam em escalas diferentes, abrangendo desde a macro } \\
\text { até a microescala. }\end{array}$ \\
\hline & $\begin{array}{l}\text { O(s) clima(s) é (são) uma composição da totalidade dos ritmos dos estados da } \\
\text { atmosfera sobre um lugar na superfície da Terra, para uma determinada } \\
\text { relação espaço-tempo. }\end{array}$ \\
\hline Pere & $\begin{array}{l}\text { O clima é uma descrição estatística que expressa as condições médias do } \\
\text { sequenciamento do tempo, ou seja, o sequenciamento das condições } \\
\text { instantâneas da atmosfera em um local. }\end{array}$ \\
\hline Silva & $\begin{array}{l}\text { ão do conjunto } \\
\text { sféricos que o } \\
\text { egião ou local. }\end{array}$ \\
\hline
\end{tabular}

Fonte: Donaire (1999), Monteiro (1971), Blair (1964), Tarifa e Azevedo (1999), Fialho (2007b) e Vianello e Alves (2000).

Nessa mesma linha, Lima e Zanella (2010) realizaram análises em unidades referentes aos conteúdos de clima nos livros didáticos do $6^{\circ}$ ano do Ensino Fundamental, adotados por dez escolas da Regional I do Município de Fortaleza (CE), e classificaram as definições apresentadas pelos livros, de acordo com os paradigmas já citados. Entre os resultados, as autoras verificaram que $50,0 \%$ dos livros analisados utilizaram a definição de clima seguindo o paradigma dinâmico, 16,7\%, o tradicional, e 33,3\%, a mescla dos dois paradigmas.

Tabela 2. Definições de Clima, segundo livros didáticos de Geografia da $6^{\text {a }}$ Série do Ensino Fundamental

\begin{tabular}{|c|c|c|c|c|}
\hline Autor(es) & Definições & $\mathbf{T}$ & $\mathbf{M}$ & $\mathbf{D}$ \\
\hline Sales, G. F. s/d & $\begin{array}{l}\text { Clima é o comportamento normal ou a sucessão habitual do } \\
\text { tempo durante o ano. }\end{array}$ & & $\mathrm{X}$ & \\
\hline Adas, M. (2001) & Clima é a sucessão habitual dos tipos de tempo. & & & $\mathrm{X}$ \\
\hline Moreira, I. (2000) & $\begin{array}{l}\text { Clima é sucessão ou o conjunto de variações dos estados do } \\
\text { tempo em um determinado lugar. }\end{array}$ & & & $\mathrm{X}$ \\
\hline Vesentini, J. W. (2001) & $\begin{array}{l}\text { Clima é o conjunto de variações de tempo de um determinado } \\
\text { lugar da superfície terrestre. }\end{array}$ & & & $\mathrm{X}$ \\
\hline Antunes, C. (1997) & $\begin{array}{l}\text { Clima é a sucessão habitual dos estados do tempo durante o } \\
\text { ano. }\end{array}$ & & $X$ & \\
\hline $\begin{array}{l}\text { Garcia, H.; Caravello, T. } \\
\text { (1998) }\end{array}$ & $\begin{array}{l}\text { Clima refere-se às condições médias da atmosfera de um } \\
\text { determinado lugar. Tais condições resultam da sucessão dos } \\
\text { estados de tempo, por um longo período, sobre esse lugar. }\end{array}$ & $\mathrm{X}$ & & \\
\hline Azevedo, G. (1996) & $\begin{array}{l}\text { Clima é a sucessão habitual dos tipos de tempo em um } \\
\text { determinado lugar. }\end{array}$ & & & $\mathrm{X}$ \\
\hline
\end{tabular}




\begin{tabular}{|l|l|l|l|l|}
\hline Lucci, E. A. (1998) & $\begin{array}{l}\text { Clima de um lugar é definido, após um longo período de } \\
\text { observações dos fenômenos meteorológicos, como a } \\
\text { temperatura, a pressão, o vento, a umidade e a chuva que } \\
\text { constituem os seus principais elementos formadores. }\end{array}$ & X & & \\
\hline $\begin{array}{l}\text { Alves, L. I. O et al. } \\
\text { (2002) }\end{array}$ & $\begin{array}{l}\text { Clima indica a sucessão dos estados de tempo em dum } \\
\text { determinado lugar ou região durante um longo período. }\end{array}$ & $X$ & \\
\hline Araújo, R et al. 1999 & $\begin{array}{l}\text { Clima é o registro do tempo atmosférico diário, durante } \\
\text { muitos anos. }\end{array}$ & $X$ & \\
\hline $\begin{array}{l}\text { Borigian, L. et al. } \\
(2001)\end{array}$ & $\begin{array}{l}\text { Clima pode ser entendido como o conjunto das condições } \\
\text { atmosféricas mais marcantes que ocorreram em um } \\
\text { determinado lugar da superfície terrestre. }\end{array}$ & $X$ & \\
\hline
\end{tabular}

Todas as definições foram retiradas dos livros de $5^{a}$ série das respectivas coleções.

Paradigma adotado nas conceituações de clima nos livros didáticos.

T - Tradicional.

M - Misto - mescla os dois paradigmas.

D - Dinâmico/Ritmo.

Fonte: Fialho (2007, p. 112).

Tomando os valores levantados citados acima, verifica-se predomínio do conceito de clima vinculado ao paradigma dinâmico nos livros didáticos, número este que destoa dos resultados obtidos por Oliveira e Colesanti (1985, p. 408), que, ao analisarem 86 obras entre o período de 1890 a 1971, identificaram apenas uma obra, o equivalente a $1,1 \%$ do conjunto da amostra, que aborda o conceito de clima de acordo com a proposta dinâmica elaborada por Max Sorre.

Ainda a respeito do livro, Missio et al. (2002) verificaram, junto às Escolas estaduais de Ensino Fundamental do município de Santa Maria/RS, como o tema de clima/tempo é abordado, tendo revelado que o livro didático é uma fonte exclusiva de consulta. Ao analisar seus conteúdos, constataram a utilização de uma linguagem superficial, que acarreta empobrecimento dos textos, além de equívocos conceituais.

Em relação à abordagem do clima, não se constatou preocupação efetiva com o dinamismo atmosférico, e apenas em alguns trechos ou capítulos das obras é explicada a inter-relação entre o comportamento dos elementos climáticos e a circulação geral e regional da atmosfera. Esta despreocupação é maior nos livros de $6^{\mathrm{a}}, 7^{\mathrm{a}}$ e $8^{\mathrm{a}}$ séries, quando os autores consultados apenas citaram as classificações dos climas de cada região, apresentando apenas a pluviometria e temperatura média, raramente citando os outros elementos que caracterizam cada clima, sua gênese ou os fatores que nele influenciam.

De forma geral, pode-se concluir que as explicações contidas nos livros são um tanto quanto superficiais e que, ainda hoje, se faz Geografia de forma essencialmente descritiva, obrigando o aluno a decorar o conteúdo, privando o estudante de raciocinar. Além de os conteúdos de tempo e clima serem complexos e abstratos (os relacionados aos paradigmas tradicional e misto), consequência do positivismo, eles favorecem a descrição, exposição, enumeração e memorização, fatos esses que, segundo Tomita e Tomita (2010), excluem a participação do aluno do processo de construção da aula.

Tal forma de "ensinar" rouba desta disciplina suas principais características: observar descrever, analisar e principalmente construir explicações e correlacioná-las. A omissão da gênese climática, formando lacunas quanto à explicação dos fenômenos, irá impossibilitar a aprendizagem do aluno e posterior utilização destes conceitos em sua vida. Além disso, não possibilita a construção de uma visão do todo, pois são feitos estudos separados, sem correlação.

Logicamente, que tal análise não define se o livro é adequado ou não para ser indicado. Segundo Pinto e Souza (2011), considerando que a seleção e a escolha do livro não dependem apenas da qualidade dos conteúdos de climatologia, é preciso que seja realizada a análise geral do livro de Geografia. Para tanto, os mesmos autores recomendam os critérios propostos por Castrogiovani (2003). 
Além da preocupação do uso de conceitos, outros problemas incidem na parte de climatologia nos livros didáticos, conforme avaliaram Steinke e Steinke (2000) em três obras utilizadas nas escolas do Distrito Federal: "Brasil: Sociedade e Espaço - Geografia - O Homem no Espaço Global (1998), de Elian Alabi Lucci; "Geografia Geral: O Espaço Natural e Socioeconômico" (1992), de Marcos de Amorim Coelho; e "Panorama Geográfico do Brasil: Contradições, Impasses e Desafios Socioespaciais" (1998), de Melhem Adas e Sérgio Adas.

Para a análise das obras, foram definidos seis critérios de avaliação: presença de erros conceituais; presença de simplificações; presença de desatualizações; presença de lacunas de informação; e utilização de ilustrações e aplicações. A partir da análise com base nos critérios citados, Tabela 3, os autores concluíram que, na maioria das obras selecionadas, assuntos relativos à climatologia são tratados de forma sucinta, valorizando as ilustrações em detrimento do conteúdo. Entretanto, essas ilustrações, na maioria das vezes, não contribuem para a compreensão do texto, pois não são sequer referenciadas. Conteúdos básicos, como aspectos astronômicos, essenciais ao entendimento da circulação atmosférica, são muitas vezes desconsiderados nas abordagens.

Por último, nesse item, não poderia deixar de falar da contribuição da climatologia no processo de compreensão das relações sociedade $x$ natureza, pois estas concepções já estiveram fundidas no passado num paradigma denominado determinismo climático. A separação formal que se estabeleceu entre essas concepções não eliminou o paradigma da bagagem cultural ocidental e a necessidade de mobilização da sociedade por uma nova forma de se relacionar com a natureza.

Segundo Collischonn e Fialho (2007), os problemas ambientais manifestados fizeram ressurgir a acepção do clima como determinante - considerando o possível colapso climático vindouro. Agora, a natureza nesta relação é uma natureza unificada pela história em benefício de firmas, estados e classes hegemônicas, e a determinação é definida pelos cenários com base em descrições matemáticas do clima e dos acontecimentos e processos sociais e culturais do futuro.

Este discurso homogeneíza, portanto, oculta e elimina os diferentes modos de os seres humanos serem e estarem no mundo. Nesse sentido, em um ambiente de formação de professores de Geografia, acredita-se que abordar as diversas facetas do aquecimento global é mais importante para um educador que propagar o alarmismo.

Ajudar o cidadão comum a entender que há uma mudança climática em curso, que demanda novas adaptações individuais e coletivas, é mais procedente do que amedrontá-lo com visões apocalípticas, que indicam suas causas como atos de vingança divina ou da própria natureza sobre o ser humano. Ao mesmo tempo, é comum as pessoas se sentirem paralisadas ou confusas com a avalanche de informações, assumindo posições comodistas do tipo: "O que eu posso fazer, se sempre foi assim?"

Tabela 3. Avaliação do conteúdo de Climatologia em livros didáticos

\begin{tabular}{|l|c|c|c|}
\hline \multicolumn{1}{|c|}{ Critérios } & \multicolumn{2}{c|}{ Obras Analisadas } \\
\hline \multicolumn{1}{|c|}{} & Marcos de A. Coelho & Melhem Adas & Elian Alabi Lucci \\
\hline Presença de erros conceituais & $\mathrm{X}$ & $\mathrm{X}$ & $\mathrm{X}$ \\
\hline $\begin{array}{l}\text { Presença de lacunas de } \\
\text { informação }\end{array}$ & $\mathrm{X}$ & $\mathrm{X}$ & $\mathrm{X}$ \\
\hline Presença de simplificação & $\mathrm{X}$ & & $\mathrm{X}$ \\
\hline Presença de desatualizações & $\mathrm{X}$ & & \\
\hline Não referência às ilustrações & & $\mathrm{X}$ & \\
\hline Não apresenta aplicações & $\mathrm{X}$ & & \\
\hline
\end{tabular}

Fonte: Steinke e Steinke (2000).

Ainda dentro desta discussão, Jacobi et al. (2011) questionam o papel da educação frente às mudanças climáticas globais, uma vez que, segundo sua alegação, o Brasil não está imune 
aos efeitos das mudanças globais. De acordo com Jacobi (2011), a International Alliance of Leading Education Institutes (IALEI) produziu um relatório global, IALEI (2009), como resultado da síntese de dez relatórios, tendo destacado quatro questões estruturais. Três destas questões diziam respeito à educação para o desenvolvimento sustentável, mas uma em especial procurava abordar o papel da educação perante a urgência das alterações do clima. Para a IALEI, as mudanças climáticas representam, do ponto de vista pedagógico, um desafio único para que se teste "a capacidade de se organizar a aprendizagem em torno de problemas caracterizados por dinâmicas sociais complexas, conhecimento incerto e riscos".

Independentemente do nível de envolvimento e centralização pelos governos, os relatórios ainda frisam que a temática das mudanças climáticas é periférica na área da educação, que se encontra dividida em duas correntes educacionais focadas na questão ambiental. A primeira é a EE (Environmental Education, Educação Ambiental), que representa uma visão instrumental fundamentada estritamente na divulgação de conhecimentos científicos, tendo em vista a mudança de comportamentos.

Já a ESD (Education for Sustainable Development, Educação para o Desenvolvimento Sustentável) estaria comprometida com o empoderamento dos educandos a fim de que estes se revelem protagonistas nas ações e na tomada de decisões. No Brasil, pode-se dizer que nos enquadraríamos na linha da Educação ambiental. Porém é necessário mudar este perfil, e um dos caminhos é a adoção de uma perspectiva construtivista de ensino, que aproxima o cotidiano do aluno dos conteúdos escolares, que podem vir a servir como fonte de solução e mitigação dos problemas ambientais locais relacionados ao clima, como enchentes, inundações, tempestades, entre outros.

\section{O USO DAS GEOTECNOLOGIAS NO ENSINO DA CLIMATOLOGIA.}

Em um mundo cada vez mais globalizado, em que a velocidade imposta pelas novas relações de trocas torna a dinâmica de relacionamentos mais complexa e baseada em redes, compreender as contradições, imposições, possibilidades e perversidades inerentes a esse processo tem sido um dos grandes desafios dos professores de Geografia.

O mundo da mobilidade, do encurtamento das distâncias e da intensa circulação de textos em diferentes suportes informacionais gera impasses e perplexidades aos docentes. A compreensão do novo cenário de abundância audiovisual e de profusão intensa de linguagens que envolvem, motivam e ensinam os estudantes, no atual período histórico, tem sido compreendida como um dos maiores desafios dos professores e das Escolas (GUIMARÃES, 2007).

Nesse cenário, a tecnologia, como um recurso, está cada dia mais presente no quotidiano das pessoas, e a cada momento está evoluindo de forma rápida, que também envelhece, em razão da velocidade imposta pelo avanço da própria tecnologia. Mas, apesar de contraditório, a presença da tecnologia na sociedade contemporânea é irreversível, e os conhecimentos que os professores têm que adquirir, quanto ao uso das novas tecnologias de informação e comunicação na sua prática pedagógica, se fazem urgentes.

Assim sendo, não basta saber ler e escrever na linguagem verbal, é necessário aprender a ler outros meios como rádio, televisão, videogame, programa multimídia, as páginas da Web, enfim, ser leitores críticos e escritores conscientes das mídias que servem como suporte a essa tecnologia. Muito embora, segundo Guimarães (2007), a incorporação de diferentes linguagens no processo de ensino em Escolas destituídas de poder simbólico na sociedade, mal equipadas, e para professores com excessiva carga de trabalho, de problemas e de desafios a serem solucionados, possa parecer um contrassenso.

Mas, por mais que sejamos céticos em relação aos resultados e às possibilidades do trabalho pedagógico, no atual contexto, não podemos deixar de questionar por que somos professores e como estamos nos construindo nessa profissão. Parto da perspectiva de que é possível 
fazermos alguma coisa diante de um cenário desolador como o que encontramos, hoje, na Escola Pública.

Nesse sentido, se aceitarmos que as tecnologias possibilitam a ampliação de um conhecimento científico ou técnico, de um "saber como fazer", de métodos e materiais para a solução de um problema, como mediadoras do processo de ensino, as tecnologias podem ser tratadas como tecnologias de informação e tecnologias de comunicação ${ }^{3}$.

$\mathrm{Na}$ atualidade, os diferentes usos das mídias se confundem e passam a ser características das tecnologias de informação e de comunicação, que mudam os padrões de trabalho, o tempo, o lazer, a educação, a saúde e a indústria. Assim, as tecnologias de comunicação, integradas à tecnologia de informação, criam uma nova sociedade, novos ambientes de trabalho, novos ambientes de aprendizagem e um novo tipo de aluno, que precisa de um novo tipo de professor.

Nesse sentido, para motivar e auxiliar o uso de tecnologias nas Escolas e melhorar a qualidade da aprendizagem, alguns estudiosos, como Carvalho (2004), propõem o uso das imagens, que, por si só, já apresentam um grande apelo visual, passam a ser instrumento para o desenvolvimento cognitivo e a consequente incorporação de novos conteúdos. Para isso, o professor terá que contar com o apoio dos recursos tecnológicos de que a Escola pode ir a dispor, como a televisão e a multimídia ${ }^{4}$, além de material desenvolvido com conteúdo específico, conforme desenvolvido por Steinke e Gomes (2011), para atender às demandas dos conteúdos de climatologia.

Agora, além da tecnologia, também ouvimos falar em geotecnologias, que, de acordo com Rosa (2005, p. 81), são o conjunto de tecnologias para coleta, processamento, análise e oferta de informação com referência geográfica. As geotecnologias são compostas por soluções em hardware, software e peopleware que juntas constituem poderosas ferramentas para tomada de decisão. Entre as geotecnologias, podemos destacar: sistemas de informação geográfica, cartografia digital, sensoriamento remoto, sistema de posicionamento global e a topografia georeferenciada.

Na pesquisa geográfica, de acordo com Divino et al. (2009), essa imposição já se coloca e assim vemos ganhar cada vez mais espaço as tecnologias que possibilitam maior rapidez no tratamento dos dados, maior capacidade de observação do espaço, nas mais variadas escalas, tanto espacial quanto temporal, possibilitando o monitoramento das mudanças que se observam na superfície da Terra.

As geotecnologias utilizam técnicas matemáticas e computacionais para o tratamento da informação geográfica no âmbito acadêmico e para planejamento político-territorial. Além de serem difundidas no meio acadêmico e político, as geotecnologias foram incorporadas ao cotidiano das pessoas e, na sociedade globalizada, inovaram as formas de se localizar.

Esse fato exige que as geotecnologias sejam também apropriadas no processo educativo, pois, em uma sociedade na qual os alunos estão sempre em contato com as mídias digitais, é necessário que a escola faça uso da linguagem digital (SILVA; CARNEIRO, 2011), até porque a popularização dessas geotecnologias, como a do sensoriamento remoto nos últimos anos, a partir da disponibilização de dados em diferentes formas na internet, em muitos casos com acesso gratuito, contribuiu para a expansão dessa técnica, permitindo seu uso para fins pedagógicos em diferentes níveis do ensino.

A realização de uma atividade didático-pedagógica no ensino da Geografia que contemple a utilização de produtos do sensoriamento remoto como recurso, segundo Godinho et. al. (2007), assume grande importância pela sua capacidade de mostrar os processos sociais espacializados, pois desencadeia questões a serem respondidas não só no tocante à geografia.

\footnotetext{
${ }^{3}$ A tecnologia de comunicação designa toda forma de veicular informação. Têm-se como meios de veiculação, incluindo as mídias mais tradicionais, os pergaminhos, os tambores na selva, os livros, o fax, o telefone, o jornal, o correio, o telex, as revistas, o rádio, a tv, o vídeo, as redes de computadores, até a internet.

${ }^{4}$ Conhecido como TV pen-drive e, computadores, de onde se podem extrair e mostrar imagens.
} 
Observar como o espaço está organizado precederá a formulação de um conjunto de indagações que, devidamente pesquisadas, responderão às questões que dizem respeito às formas como se dão as relações na sociedade e como esta se apropria do espaço e (re) produz conflitos.

Saussen e Machado (2004) salientam que o uso de imagens de satélite no estudo da Geografia em sala de aula contribui para a melhora da didática, significando o uso de tal tecnologia, bem como de seus produtos, na medida em que promove a diversificação e motivação do aluno, que poderá desvendar o espaço geográfico da própria região com imagens de satélite que permitem identificar o uso e a cobertura da terra, o desenho urbano, os impactos ambientais, entre outros aspectos. A partir disso, possíveis soluções poderão ser desenvolvidas com o corpo discente, o que poderá vir a desenvolve o sentimento de autonomia e compromisso no processo de decisão.

Em relação ao trabalho com as imagens de satélite meteorológico, Rocha et al. (2002) apontam que, entre os principais fatores e elementos climáticos passíveis de interpretação visual com apoio do Sensoriamento Remoto, estão as massas de ar, o albedo, temperatura dos mares e oceanos, Ciclones e Anticiclones, a presença da umidade, as correntes marítimas, latitude e altitude, ZCIT, vegetação, entre outros.

Partindo desse princípio, Maia (2011) propõe a interpretação destas imagens com base na integração das propostas de Ferreira (2002 apud MAIA, 2011), que busca identificar as tonalidades e formas das imagens, enquanto Simielli (2001) propõe a possibilidade de trabalhar em três níveis: a) Localização e análise - indica a distribuição das massas e frentes presentes nas imagens de satélite meteorológico e nos mapas climáticos; b) Correlação permite a combinação das imagens de satélite meteorológico com um, dois ou mais mapas climáticos; e c) Síntese - apresenta as relações entre as imagens de satélite meteorológico e os mapas climáticos, apresentando uma síntese escrita dos elementos climáticos e sua repercussão espacial.

Nesse sentido, os professores devem aproveitar a oportunidade do apelo visual das imagens e desenvolver propostas de atividades que possam agregar informações e despertar o interesse, a partir da conjugação de dados da dinâmica atmosférica representada pela imagem e pelos mapas climáticos do Brasil, que devem estar sincronizados no mesmo dia e horário, para possibilitar a correlação da dinâmica atmosférica com o comportamento dos elementos climáticos no território brasileiro, conforme pode ser visualizado pela Figura 1.

Ainda com base na proposta do estudo do clima, a partir do uso de imagens de satélites meteorológicos, Jatobá (1997) propõe que os conteúdos específicos de climatologia podem ser explorados pelo professor de Geografia, abordando: A) Os fatores geográficos e suas influências sobre os climas; B) A circulação atmosférica e o andamento do tempo; e 3) Os tipos de climas e os regimes pluviométricos, além de poder empregar as imagens, na prática do aluno, para identificar os sistemas atmosféricos. 

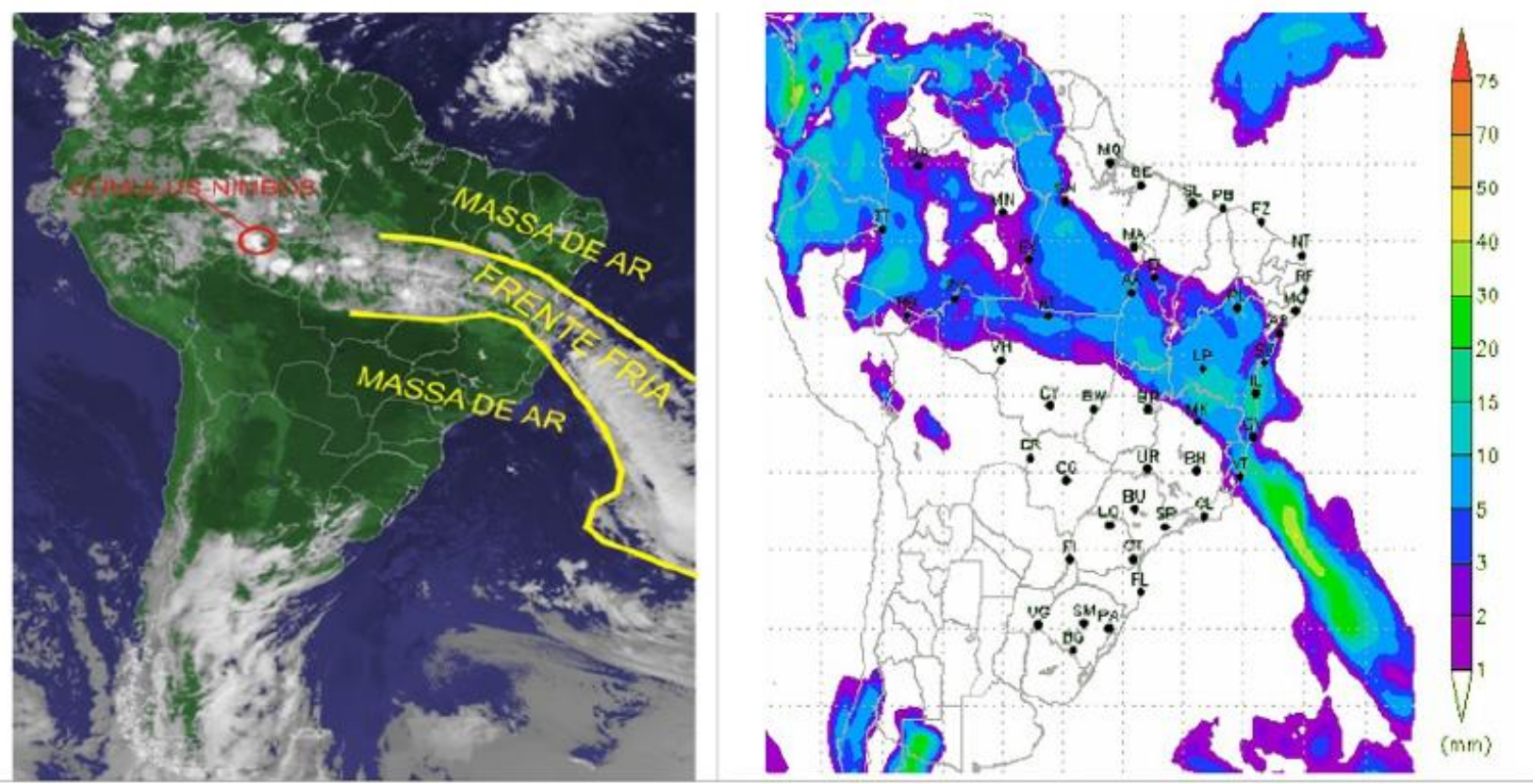

Figura 1. Imagem de satélite meteorológico (lado esquerdo) e o mapa de precipitação (lado direito) captados às 12 horas do dia 27 de outubro de 2010.

Fonte: Maia (2011, p. 86).

O uso das imagens meteorológicas pela sociedade em geral também apresenta um incremento. Tanto é assim que os meios de comunicação procuram investir na melhor qualificação da informação meteorológica para previsão de curto prazo. A consequência do aumento do interesse é o aumento do faturamento das empresas do setor ${ }^{5}$, que chegou a 100 milhões de reais em 2002 (FIALHO, 2002).

Em 2010, o site Climatempo investiu cerca de 40 milhões de reais, tendo a expectativa de crescimento acima dos 20,0\%. Apesar do grande interesse nessa área, estes mesmos sítios, quando da ocorrência de eventos atmosféricos extremos, não fornecem esclarecimentos sobre a origem do fenômeno, muito raramente mostram as repercussões.

O detalhamento de tais informações, muitas vezes, está restrito a sítios de órgãos governamentais, como o INPE e o INMET, que têm suas informações retrabalhadas e disponibilizadas em inúmeros blogs de divulgação científica, Tabela 4, que reproduzem, geralmente, os fenômenos atmosféricos extremos, que atingem as cidades dos responsáveis pelo gerenciamento destes blogs ${ }^{6}$, muitas vezes cidadãos interessados em divulgar os problemas do local atingido, através do olhar do morador. Esse trabalho de disseminação agora é visto como de grande importância, pois os grandes veículos de comunicação procuram estes sítios para obter exclusividade na cobertura de algum evento nessas informações.

Essa preocupação crescente também reflete a influência do clima sobre a organização do tempo e do espaço das pessoas. Logicamente, dependendo do nível de desenvolvimento de cada país, o ritmo climático tem maior influência na atividade econômica, principalmente, onde a agricultura é a maior fonte de arrecadação de divisas.

No caso do Brasil, país de dimensões continentais, eventos climáticos extremos, positivos e negativos afetam o norte e o nordeste com as secas, e com as enchentes o centro sul. Essa espacialização, notadamente, encontra desigualdades regionais, em que o "sul maravilha" apresenta a maior concentração dos recursos disponíveis, diferentemente do Nordeste e da

\footnotetext{
${ }^{5}$ Climatempo, Somar e a The Weather Channel prestam serviços às emissoras de televisão e jornais.

${ }^{6}$ A atualização não é constante, obedecendo à sazonalidade dos eventos climáticos significativos.
} 
Amazônia onde se constata ainda um grande vazio demográfico. Essas diferenças se refletem na distribuição de conteúdo técnico.

Tabela 4. Sítios de divulgação sobre previsão de tempo e discussão sobre clima.

\begin{tabular}{|l|l|}
\hline \multicolumn{1}{|c|}{ Sítios } & \multicolumn{1}{c|}{ Endereço eletrônico } \\
\hline Clima Brasil & http://climabrasil.blogspot.com.br/ \\
\hline Metsul & http://www.metsul.com/blog2012/ \\
\hline Observatório do clima & http://blog.oc.org.br/ \\
\hline Fórum Clima & http://www.forumempresarialpeloclima.org.br/ \\
\hline Apolo 11 & http://www.apolo11.com/ \\
\hline Meteo Brasil & http://www.meteobrasil.com.br/ \\
\hline Master & http://www.master.iag.usp.br/ \\
\hline Simepar & http://www.simepar.br/ \\
\hline Canal do Tempo & http://br.weather.com/ \\
\hline Somar & http://www.somarmeteorologia.com.br/index.html \\
\hline Labmet (univap) & http://www.labmet.univap.br/ \\
\hline Marinha do Brasil & https://www.mar.mil.br/dhn/chm/meteo/index.htm \\
\hline Funceme & http://www.funceme.br/ \\
\hline Ana & http://www.ana.gov.br/ \\
\hline Redemet & http://www.redemet.aer.mil.br/ \\
\hline Decea & http://www.decea.gov.br/ \\
\hline
\end{tabular}

Em virtude disso, os alunos de Ensino Fundamental e Médio que têm um maior acesso a informações pela mídia procuram seus professores para elucidar dúvidas advindas de informações não compreendidas. Nesse momento, cabe ao professor aproveitar a curiosidade do corpo discente para conseguir manter a motivação por meio de orientação de trabalhos em classe e pesquisa fora do ambiente escolar para promover o desenvolvimento do aprendizado.

No entanto, é necessário que o professor tenha sob domínio o conhecimento, no caso, a climatologia, que, infelizmente, ainda é distinta entre a graduação na universidade e os bancos escolares do Ensino Médio e Fundamental, pois não corresponde à demanda dos estudantes, que não reconhecem sua realidade local, retratada nos livros, nos exemplos e exercícios.

Esse fato é grave, uma vez que o papel da Universidade não é reproduzir conhecimento, mas (re)construir, de uma maneira criteriosa e crítica, um novo saber. Conforme Sant' Anna Neto (1998), faz-se necessário repensar as ementas programáticas nos cursos de graduação, pois o mesmo autor verifica um fosso entre as linhas de pesquisa desenvolvidas, o grau de especialização dos docentes e as práticas pedagógicas, além dos conteúdos programáticos que, em grande parte, não correspondem mais à realidade das necessidades de formação dos geógrafos, tanto na docência quanto na pesquisa.

\section{ENTRE O PRODUZIDO E O ENSINADO.}

Em relação à produção de pesquisa na área de clima e ensino, ela pode ser verificada no levantamento que fiz com base nos anais dos simpósios brasileiros de climatologia geográfica, realizado até então entre os anos de 1992 e 2010.

Todavia, embora a Figura 2 possa nos levar a pensar de imediato em um aumento percentual da participação de trabalhos na área de ensino, também é possível dizer que o acréscimo é pouco significativo, em razão da grande variação registrada entre os anos de 2006 (VII SBCGRondonópolis) e 2010 (IX SBCG-Fortaleza), o que se confirma quando se observa o índice de correlação $\left(R^{2}\right)$ do gráfico que identifica um baixo índice de confiança de confiança, com 
apenas 0,2306, o que também nos leva a dizer que a temática do ensino em clima não aumentou, mantendo-se em torno de 3,0\%, conforme atesta Fialho (2010).

Porém, isso não significa que o perfil dos trabalhos não tenha sido modificado. Entre 1992 e 2002, a maior parte das pesquisas estava voltada para o ensino do clima na academia, aparecendo, esporadicamente, algum artigo voltado ao desenvolvimento e à avaliação do ensino do clima por meio da análise de livros didáticos. Mas a partir de 2004, há um aumento nos estudos voltados a intervenções da escola, fato esse que coincide com dois momentos institucionais importantes na universidade, através de uma mudança de política do MEC, que são: a valorização da Extensão universitária e a criação dos Programas Institucionais de Bolsa para Iniciação à Docência (PIBID), muito parecido aos moldes do Programa de Educação Tutorial (PET).

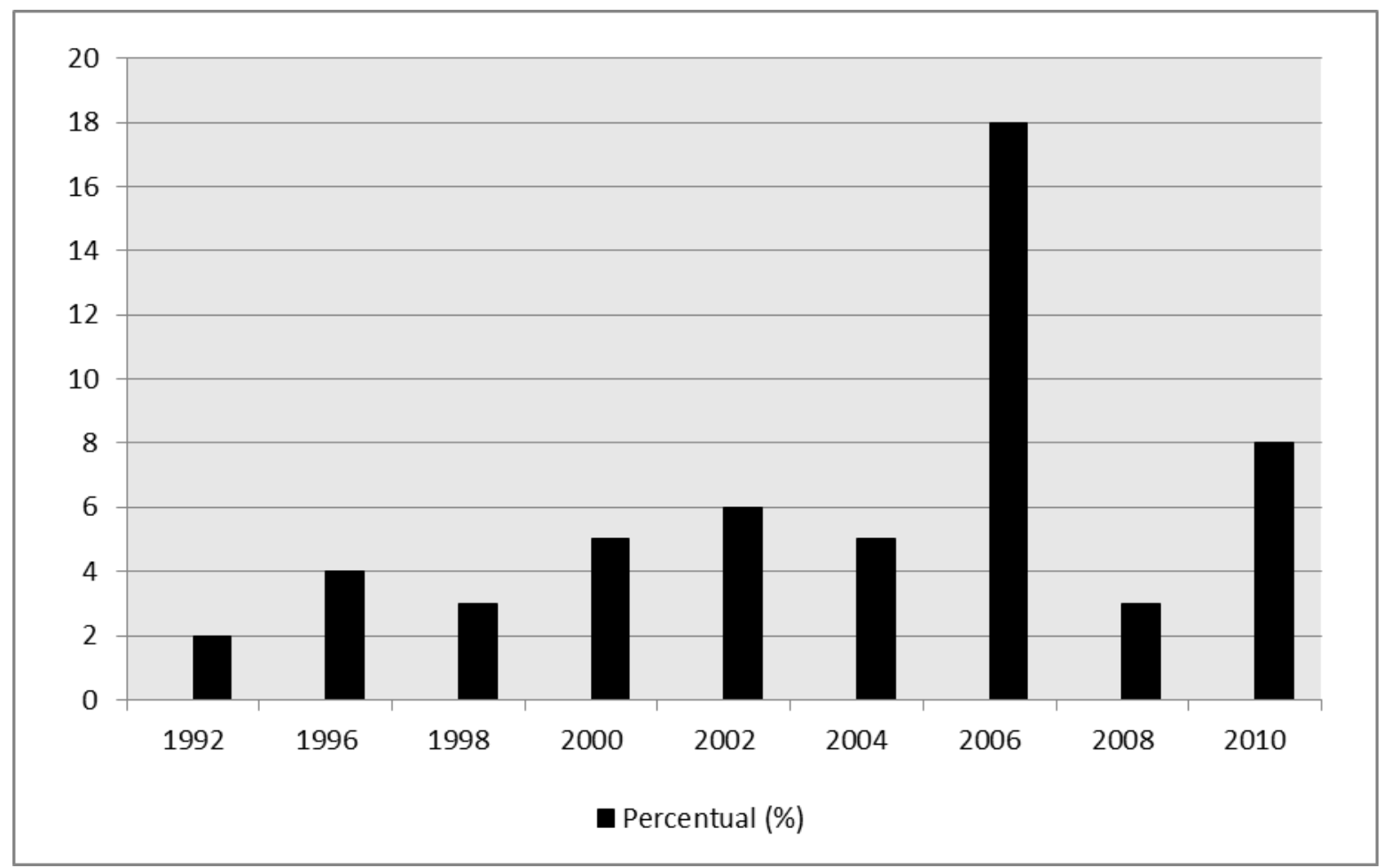

Figura 2. Evolução percentual dos trabalhos publicados, na temática Ensino e Clima, nos anais dos Simpósios Brasileiros de Climatologia Geográfica entre 1992 e 2010.

Fonte: Anais dos Simpósios Brasileiros de Climatologia (1992-2010).

O investimento na academia com o desenvolvimento de pesquisa na área de ensino em climatologia e a apresentação de novas possibilidades de ensino, com argumentado por Fialho (2002), buscam valorizar o saber construído pelo graduando que não se restringe ao trabalho de campo com medidas de temperatura horárias, através da percepção para exercitar a interpretação e análise da importância da disposição dos objetos sobre o espaço, com intuito de pensar em alternativas urbanísticas mitigadoras. Castro (1997) afirma que as observações diárias, a partir da sensibilidade, estimulam o uso da capacidade que o organismo humano tem de sintetizar as condições do tempo meteorológico. Mas ainda existe um grande abismo entre a universidade e a escola!

A compreensão desse hiato não é nova, pois, segundo Sant'anna Neto (2000), o problema existe por causa de vários fatores, entre eles: A) a estrutura curricular; B) a formação dos professores; e C) a falta de integração dos conteúdos climatológicos com os demais do extenso e diversificado rol de disciplinas que compõem a ciência geográfica, tanto na escola, quanto na universidade.

Apesar disso, o problema não está apenas na comunicação entre a escola e a universidade, mas na própria estrutura da instituição universitária, que promove, através da estrutura 
curricular, uma desarticulação e uma comunicação entre as disciplinas da grade, além de a localização da disciplina de climatologia estar no primeiro ano de graduação, quando o acadêmico, ainda imaturo, pouco compreende as articulações do conteúdo apresentado com outras áreas do saber geográfico.

Ainda sobre o currículo, Sant'anna Neto (2002), agora detidamente sobre a ementa dos programas da disciplina de climatologia, observa que em geral os conteúdos são caracterizados pela descrição de fenômenos atmosféricos, pelo estabelecimento de regras e leis gerais, que explicam a circulação da atmosfera, através do comportamento dos elementos do clima, muitas vezes de forma compartimentada, bem como a apresentação dos sistemas de classificação climática e a valorização acerca dos conceitos fundamentais da climatologia, que são em grande parte desconectadas da realidade social.

Mas apesar dessas dificuldades apresentadas no meio acadêmico, muitos professores/pesquisadores, responsáveis pela cadeira de Climatologia, vêm se esforçando no desenvolvimento de atividades que busquem conjugar o ritmo à dinâmica social. Faz-se necessária a realização de experimentos de campo, através da criação de equipamentos alternativos, como forma de construir o conhecimento, segundo argumentam Aguiar (1995), Machado (1996), Castro (1997), Collischonn (1998 e 2007), Abreu (1999), Brandão, Thurler e Araújo (1999) e Ely (2000).

Estes trabalhos destacam a necessidade de valorização da concepção didática baseada na experimentação no ensino de climatologia em cursos de Geografia. Em grande parte destes trabalhos, a experiência didática tem demonstrado que a leitura e a interpretação de dados e informações fornecidas pela meteorologia não garantem a apreensão do conhecimento relacionado à climatologia, conforme atesta Lima (2006). O aluno dificilmente reconstrói o processo da descoberta, elaboração e utilização dos instrumentos que dão origem a estes dados se não aprender como é o seu funcionamento e não acompanhar um levantamento de dados. Normalmente ocorre certa mitificação da etapa de medição dos fenômenos.

Isto ocorre porque, por um longo período, segundo Collischonn (2007), a formação acadêmica em geografia afastou-se da experimentação. E agora com os Parâmetros Curriculares Nacionais para os Cursos de Geografia no país, aprovados em 2001, há uma revalorização da apropriação de conceitos científicos através da experimentação, destacando a necessidade de decodificar o conhecimento elaborado pela pesquisa para o processo de ensino aprendizagem da geografia.

Agora se considerarmos que o acadêmico e o aluno do ensino médio e fundamental, em grande parte provenientes de camadas populares, entendem que o aprender seja apenas uma forma de satisfazer as exigências da escola e da universidade para ter acesso à série ou período seguinte, pois o saber é percebido como intangível e não pragmático, resta pouco para iniciar uma nova forma de despertar esses alunos, que, segundo Charlot (op.cit), julgam mais importantes ou significativos os saberes que dizem respeito à esfera relacional, por eles adquiridos em boa parte no meio familiar e em seu círculo imediato.

Nesse sentido, os saberes populares ou ditos populares ${ }^{7}$ são uma alternativa frente ao ensino de climatologia, pois permitem aos alunos desvendar os "mistérios" que povoam as mentes e que muitas vezes se tornam verdades sem uma reflexão anterior. Essa alternativa vem sendo pesquisada por Maia (2010), que relata a possibilidade de se fazer entender o sentido de cada um, buscando uma comparação com o dia a dia dos alunos, chamando a atenção para a observação da natureza, ou seja, do comportamento dos animais e plantas, tomando como referências principais a reflexão e a descrição das nuvens, percebendo, assim, a provável mudança de tempo. E esse comportamento, segundo Alonso e Garcia (2007, p. 2), vem sendo exercitado: "...desde los tiempos más remotos.(...). El arte de conocer el tiempo y sus

\footnotetext{
7 Um provérbio popular é uma máxima. Também é conhecido como adágio, anexim, ditado. É máxima sentença, popularizada ou consagrada pelo uso, a qual é menos vulgar que o adágio e de moral mais segura e severa.
} 
variables tiene unos orígenes poco claros e inmersos en la mitología, no se parece en nada a los métodos científicos que emplean la tecnología moderna...".

Essa revalorização desses ditos populares, Tabela 5 , é muitas vezes ignorado por meteorologistas, em função, segundo Sartori (2005, p. 2), do avanço da tecnologia disponível. Porém, muitos deles continuam a ser utilizados, principalmente entre as populações rurais, pois resultam da sensibilidade humana e do tempo de permanência do homem em um mesmo ambiente, o que lhe permite desenvolver uma específica percepção do espaço vivido ou vivenciado e, com isso, a cognição ambiental.

Entretanto, muito recentemente, alguns pesquisadores das ciências atmosféricas vêm procurando compreender a dinâmica de entendimento sobre o tempo, conforme relatam Folhes e Donald (2007), que trataram de interpretar as manifestações da natureza associadas com as previsões meteorológicas, atribuídas às pessoas que têm aguçada sensibilidade de observação, caso dos sertanejos do Ceará.

Tabela 5. As crendices populares acerca do tempo.

\begin{tabular}{|c|c|c|}
\hline $\begin{array}{c}\text { Ditos } \\
\text { Populares }\end{array}$ & País de Origem & Crendices \\
\hline \multirow{5}{*}{$\begin{array}{l}\text { Aves e } \\
\text { insetos }\end{array}$} & Estados Unidos & Cuco cantando todo o dia, ano frio anuncia. \\
\hline & Brasil (NE) & Acuã cantou, inverno chegou. \\
\hline & Rússia & Garças cantando em voo ameno, sinal de outono ameno. \\
\hline & Rússia & Mosquitos no fim do outono, inverno risonho. \\
\hline & Brasil & Cigarra cantou, calor chegou. \\
\hline \multirow{7}{*}{$\begin{array}{c}\text { Peixes, } \\
\text { Répteis } \\
\text { e Mamíferos }\end{array}$} & França e Alemanha & O peixe salta antes da tempestade. \\
\hline & $\begin{array}{l}\text { França, Espanha e América } \\
\text { Hispânica }\end{array}$ & Silvar da cobra, chuva de sobra. \\
\hline & Índia & $\begin{array}{c}\text { Rã cantando em campo aberto, chuva três horas por } \\
\text { perto. }\end{array}$ \\
\hline & Espanha & Sapo cantando ao anoitecer, bom tempo vai fazer. \\
\hline & Brasil e Espanha & Cobras tossindo espirrando, o tempo está mudando. \\
\hline & Holanda e Bélgica & Gato se lambe é sinal de chuva. \\
\hline & Irã & Quando os carneiros abanam as orelhas, é sinal de chuva. \\
\hline \multirow{6}{*}{$\begin{array}{c}\text { Dias e } \\
\text { Estações }\end{array}$} & Bélgica & Gelo em setembro, suave dezembro. \\
\hline & $\begin{array}{l}\text { Espanha e América } \\
\text { hispânica }\end{array}$ & Inverno chuvoso, verão caloroso. \\
\hline & Japão & $\begin{array}{l}\text { Quando as folhas do trigo nascem estreitas e curtas, é } \\
\text { sinal de muita neve no inverno. }\end{array}$ \\
\hline & Brasil & $\begin{array}{l}\text { Inverno quente, feijão doente: verão chuvoso, feijão } \\
\text { formoso. }\end{array}$ \\
\hline & Espanha e Reino Unido & Março ventoso e abril chuvoso, maio formoso. \\
\hline & China & $\begin{array}{l}\text { Céu avermelhado de manhã, chuva de tarde; tarde } \\
\text { avermelhada, tempo bom. }\end{array}$ \\
\hline
\end{tabular}

Fonte: Adapatado de Clousse (1973, p. 61-62). Revista O Correio da Unesco. Ano 1, n. 10-11, outubro de 1973.

De acordo com Alves (2005), entre 90,0 e 95,0\% dos ditos populares sobre a atmosfera são corretos, pois explicam a exatidão dos ditados pelo fato de se basearem na observação e repetição dos fenômenos meteorológicos ao longo de séculos. O meteorologista defende por isso que não se deve separar o saber popular da ciência, que pode ser agregado ao saber acadêmico, na medida em que ele pode auxiliar no esclarecimento do funcionamento dos processos meteorológicos, através de práticas pedagógicas utilizáveis tanto na escola como na universidade. Entre os exemplos, pode-se citar a organização de visitas técnicas a uma estação meteorológica, conforme Collischonn (2010) e Silva et al. (2010) realizaram em Bento 
Gonçalves-RS e Jataí-GO, respectivamente, ou de acordo Muniz e Caracristi (2010), desenvolver aparelhos meteorológicos de baixo custo ou alternativos.

\section{PARA NÃO FINALIZAR...}

A partir da década de 1970, os livros didáticos ampliaram sua importância no cenário educacional brasileiro, ao mesmo tempo em que ocorreu uma crescente desqualificação profissional dos professores, tanto no que diz respeito à formação quanto à remuneração desses profissionais. Nesse sentido, pode-se afirmar que o empobrecimento econômico e cultural dos professores da educação básica - que se reflete em desprestígio social cada vez maior da categoria - tem sido acompanhado por uma crescente dependência do livro didático, que, conforme Steinke e Steinke (2000) verificaram, apresenta equívocos conceituais e no uso de imagens.

Então surge uma questão: considerando que a maior parte dos autores dos livros didáticos em Geografia são graduados, em grande parte, segundo Castro e Salgado (2011, p. 96), na Universidade de São Paulo (USP) e na Universidade Estadual Paulista Julio Mesquita Filho (Unesp-Rio Claro), locais de origem da climatologia geográfica brasileira, por que certos descuidos continuam a ocorrer?

Por falta de conhecimento da dinâmica da atmosfera e seu ritmo não pode ser. Selles e Ferreira (2004), ao analisarem as representações das estações encontradas em quinze livros didáticos investigados de ciências, também se espantaram com a persistência de visões distorcidas da realidade tropical.

A explicação para tal fato se deve em parte ao processo histórico de disseminação dos livros didáticos no Brasil, que, inicialmente, eram traduzidos de maneira acrítica por professores, muitos deles do Colégio Pedro II, que, além de dominarem algum idioma estrangeiro, geralmente o francês, foram tradutores e, posteriormente, tornaram-se autores de livros didáticos. Isso nos faz supor que suas fontes de referência e, mais especificamente, suas fontes de ilustrações sobre as estações do ano foram essas obras estrangeiras, com representações típicas de países europeus. Nesse contexto, os livros didáticos em Geografia que abordam a climatologia, será que são influenciados por esse processo histórico cultural de formação das representações dos fenômenos meteorológicos?

Caso isso ocorra, então teremos que nos aprofundar na discussão sobre a transposição didática do clima nos bancos escolares. Esse conceito permite analisar como o saber é transposto de uma esfera de conhecimento para outra esfera, como também possibilita analisar quais transformações ocorrem nesse percurso, assim como quais os atores ou elementos que interferem nessas transformações.

Segundo Boligian (2003), a transposição apresenta-se como uma teoria sobre o que ocorre com o saber quando ele percorre o "caminho" entre as esferas de conhecimento, isto é, quando parte da esfera científica, onde é produzido, ruma à esfera escolar, onde é ensinado.

Proveniente das reflexões de Verret (1975) e outros que procuraram denunciar os diferentes mecanismos de transposição de saberes ditos especializados em saberes escolares, os programas escolares, modos de planejamento dos cursos, contribuíram assim para desnaturar de algum modo os saberes científicos e deles oferecer uma visão enviesada aos alunos. Porém transferir o saber acadêmico para o escolar, se isso for possível, apresenta alguns problemas operacionais, que, segundo Verhaeghe et al. (2010, p. 86), são: A) Dessincretização: Um saber que tem um sentido quando está imbricado em uma rede conceitual perde parte desse sentido quando isolado dessa rede; B) Despersonalização: O saber é descontextualizado, retirado do seu quadro sociocultural. Isto modifica a percepção que podemos ter deles; C) Programabilidade: Os saberes, às vezes, tendem, no meio escolar, a ser apresentados em 
uma relação linear, enquanto na origem, eles mais frequentemente estão imbricados em uma rede complexa; D) Modo de difusão; e E) Práticas sociais de referencial.

Essa preocupação com o diálogo entre a universidade e a escola, acredito que deva ser um nova forma de orientar as investigações do ensino do clima, pois a preocupação inicial de transmitir o conteúdo já não mais basta. Devemos, pois, construir e reconstruir os caminhos do processo de aprendizagem, que, muitas vezes, pode apresentar obstáculos que estejam além da escola e da disciplina.

\section{Agradecimentos}

- Ao bolsista de Iniciação Científica (CNPq/PIBIC), Rafael de Souza Alves, graduando do curso de Geografia.

- À Funarbe, que, através do Programa de bolsas de qualidade em pesquisa de excelência para jovens docentes pesquisadores (FUNARPEX), edital 2011/2012, que patrocina o projeto A Importância do sítio no caráter climático nas cidades localizadas na Zona da Mata Mineira, nos possibilitou o desenvolvimento da reflexão do ensino do clima nos bancos escolares.

- À minha esposa Edmar Maria do Bomfim e à minha filha Letícia Maria do Bomfim Fialho, que contribuem com a nossa caminhada acadêmica, permitindo nos isolarmos em alguns momentos do convívio e de suas presenças para que possamos desempenhar nossa atividade de pesquisa e escrita, que tomam um grande tempo. A vocês, o meu amor e muito obrigado.

\section{Referências bibliográficas}

ABREU, M. L. de et al. Estudos das variáveis climáticas na Universidade Federal de Minas Gerais. In: SIMPÓSIO BRASILEIRO DE GEOGRAFIA FÍSICA APLICADA, 8, 1999. Belo Horizonte. Anais..., Belo Horizonte: UFMG, 1999, p. 7-9.

ALVES, C. Ditados populares sobre o tempo são verdadeiros. Disponível em: http://www.cienciahoje.pt/index.php?oid=1412\&op=all.Acesso em 28 ago. 2012.

AGUIAR, F. E. O. Alterações no Clima Urbano de Parintins, cidade do médio Amazonas. In: SIMPÓSIO BRASILEIRO DE GEOGRAFIA FÍSICA APLICADA, 7, 1995. Goiânia. Anais..., Goiás: UFG, 1995, p. 19-20.

ALONSO, J. A.; GARCIA, J. A. El arte de conocer el tiempo. Lurralde. Ingeba, n. 30, v. 1, p. 73-93, 2007. Disponível em: http://www.ingeba.org/lurralde/lurranet/lur30/30amesto/30amesto.htm. Acesso em 27 ago. 2012.

BARROS, J. R.; ZAVATINI, J. A. Bases conceituais em climatologia geográfica. Mercator, Fortaleza, v. 8, n. 18, p. $255-261,2009$.

BERTRAND, George; BERTRAND, Claude. Não há território sem terra. In: Uma Geografia transversal e de travessias: O meio ambiente através dos territórios e das temporalidades. (org.) PASSOS, Messias Modesto dos. Maringá: Massoni, p. 187-192, 2007, 332p.

BOLIGIAN, L. A transposição didática do conceito de território no ensino de geografia. In: ENCONTRO NACIONAL DE PRÁTICA DE ENSINO DE GEOGAFIA, 7, 2003. Vitória. Anais..., Espírito Santo: UfES, 2003, cd-rom.

BRANDÃO, A. M. P. M., THURLER, E. R.; ARAÚjO, S. I. Educação geográfica em escolas do município: O meio ambiente em destaque. in: SIMPÓSIO BRASILEIRO DE GEOGRAFIA FÍSICA APLICADA, 8, 1999. Belo Horizonte. Anais..., Minas Gerais: UFMG, 1999, p. 72-73.

CALLAI, H. C. Políticas públicas e educação: Desafios da educação formal. In: ENCONTRO NACIONAL DE ENSINO DE GEOGRAFIA, 6, 2007. Uberlândia. Anais..., Minas Gerais: AGB, 2007, cd-rom.

CAMPOS, R. R. Cinema, geografia e sala de aula. Estudos Geográficos, Rio Claro, n. 4, v. 1, p. 1-22, 2006.

CASSAB, C. Reflexões sobre o ensino de Geografia. Revista de Geografia: Ensino e Pesquisa. Santa Maria, v. 13, n. 1, p. 43-50, 2009. Disponível em: http://cascavel.ufsm.br/revistageografia/index.php/revistageografia/article/viewFile/50/43

CASTRO, M. G. S. A climatologia e os professores de Geografia de $1^{0}$ e $2^{0}$ Graus. In: SIMPÓSIO BRASILEIRO E FORUM LATINO-AMERICANO DE GEOGRAFIA FÍSICA APLICADA, 7 e 1, 2002. Curitiba, Anais..., Paraná: UFPR, 2002, cd-rom.

CASTRO, F. T.; SALGADO, A. A. R. O espaço da Geografia Física na educação básica do município de Belo Horizonte: Uma análise dos livros didáticos. Geografias, Belo Horizonte, v. 7, n. 1, p. 88-98, 2011. CASTROGIOVANNI, A. C. A questão do livro didático em Geografia: elementos para uma análise. In: CASTROGIOVANNI, A. C. et al. (orgs).: Geografia em sala de aula: práticas e reflexões. 4 ed. Porto Alegre: Editora da UFRGS, 2003, p, 132-135. 
ISSN: 1980-055x (Impressa) 2237-8642 (Eletrônica)

CIRINO. M. M.; SOUZA, A. R. O discurso de alunos do Ensino Médio a respeito da "Camada de Ozônio". Ciência e Educação, Bauru, v. 14, n.1, p. 115-134, 2008.

COLLISCHONN, E. Variações da temperatura e umidade relativa do ar nos ambientes da Universidade de Santa Cruz do Sul num dia de verão: Uma experiência de aprendizagem em climatologia. in: ENCONTRO ESTADUAL DE GEOGRAFIA, 18, 1998. Santana do Livramento, Anais..., Rio Grande do Sul: AGB-Porto Alegre, 1998, p. 120-122.

COLLISCHONN, E. Variação temporal e espacial da precipitação - uma experiência didática. In: SIMPÓSIO BRASILEIRO DE CLIMATOLOGIA GEOGRÁFICA, 5, 2002. Curitiba. Anais..., Paraná: UFPR, 2002, cd-rom, p. 1130-1138.

COLLISCHONN, E.; FIALHO, E. S. Problematizando a inscrição sociocultural do pensamento "politicamente correto" em tempos de mudanças climáticas. Boletim Gaúcho de Geografia, Porto Alegre, n. 33, p. 191-214, 2007. Disponível em: http://agb-portoalegre.webnode.com.br/bgg-33/. Acesso em 29 ago. 2012.

COLLISCHONN, E. Superando a educação bancária na formação de professores de geografia através da experimentação. Revista Ágora, Santa Cruz do Sul, v. 13, n. 1, p. 205-228, 2007. Disponível em: http://www.sumarios.org/sites/default/files/pdfs/117-307-1-pb.pdf. Acesso em 29 ago. 2012.

COLLISCHONN, E. Visita à estação meteorológica: Evolução de uma prática de ensino. In: SIMPÓSIO BRASILEIRO E CLIMATOLOGIA GEOGRÁFICA, 9, 2010. Fortaleza. Anais..., Ceará: UFC, 2010, cd-rom.

LEAL, D. C.; NERY, J. T. Climatologia vai à escola. In: SIMPÓSIO BRASILEIRO DE CLIMATOLOGIA GEOGRÁFICA, 9, 2010. Fortaleza. Anais..., Ceará: UFC, 2010, cd-rom.

DIVINO, A. C.; ZAIDAN, R. T.; AFFONSO, E. P. Geotecnologias Aplicadas ao Ensino de Geografia: uma proposta metodológica. Revista Virtu, Juiz de Fora, v. 1, n. 8, p. 1-13, 2009. Disponível em: http://www.ufjf.br/virtu/files/2009/11/9-geotecnologia-aplicada-UFJF.pdf. Acesso em 18 ago. 2012.

ELY, D. F. Caracterização do ambiente microclimático do Campus da Universidade Estadual de Londrina (PR) na situação de inverno do ano de 1999. Geografia, Londrina, v. 9, n. 2, p. 143-150, 2000.

FIALHO, E. S. Classificação climática: Uma atividade prática no estudo da climatologia geográfica à luz da percepção no campus da PUC-Rio. In: SIMPÓSIO BRASILEIRO E CLIMATOLOGIA GEOGRÁFICA, 5, 2002. Curitiba. Anais..., Paraná: UFPR, 2002, cd-rom, p. 323-332.

FIALHO. E. S. Práticas do ensino de climatologia através da observação sensível. Revista Ágora, Santa Cruz do Sul, v. 13, n. 1, p. 105-123, 2007a.

FIALHO, E. S. Inconstâncias climáticas: uma discussão conceitual. Revista Tamoios, São Gonçalo-RJ, v. 4, n. 2, 2007b. $\quad$ Disponível h: em://www.epublicacoes.uerj.br/index.php/tamoios/article/viewFile/625/655. Acesso em 29 ag. 2012.

FIALHO, E. S. A pesquisa climatológica realizada por geógrafos brasileiros. Revista Brasileira de Climatologia, Curitiba, v. 6, n. 6, p. 194-212, $2010 . \quad$ Disponível em: http://ojs.c3sl.ufpr.br/ojs2/index.php/revistaabclima/article/viewFile/25618/17164. Acesso em 24 ago. 2012. FIALHO, E. S. A Geografia escolar e as questões ambientais. Revista Ponto de Vista, Viçosa, v. 5, n. 5, p. 49-63, 2008. Disponível em: http://www.coluni.ufv.br/revista/docs/volume05/geografia.pdf. Acesso em 30 ago. 2012.

FOLHES, M. T.; DONALD, N. Previsões tradicionais de tempo e clima no Ceará: O conhecimento popular a serviço da ciência. Sociedade \& Natureza, Uberlândia, n. 19, v. 2, p. 19-31, p. 19-31, 2007.

GEBRAN, R. A. A Geografia no ensino fundamental: trajetória histórica e proposições pedagógicas. Revista Científica da Universidade do Oeste Paulista. Presidente Prudente, v. 1, n. 1, p. 81-88, 2003. Disponível em: http://revistas.unoeste.br/revistas/ojs/index.php/ch/article/viewFile/186/90. Acesso em 23 ago. 2012.

GODINHO, J.; FALCADE, I.; AHLERT, S. O uso de imagens de satélite como recurso didático para o ensino de Geografia. In: SIMPÓSIO BRASILEIRO DE SENSORIAMENTO REMOTO, 13, 2007. Florianópolis. Anais..., Santa Catarina: Inpe, 2007, p. 1485-1489. Disponível em: http://marte.dpi.inpe.br/col/dpi.inpe.br/sbsr\%4080/2006/11.16.00.59.27/doc/1485-1489.pdf. Acesso em 25 ago. 2012.

GUIMARÃES, I. Fazer criativo e a incorporação de diferentes linguagens no ensino de Geografia. In: ENCONTRO NACIONAL DE ENSINO DE GEOGRAFIA, 6, 2007. Uberlândia. Anais..., Minas Gerais: AGB, 2007, cd-rom.

JACOBI, P. R.; GUERRA, A. F. S.; SULAIMAN, S. N.; NEPOMUCENO, T. Mudanças climáticas globais: a resposta da educação. Revista Brasileira de Educação, Rio de Janeiro, v. 16, n. 46, p. 135-268, 2011. JATOBÁ, L. O uso de imagens de satélite no ensino de climatologia no nordeste brasileiro. In: SIMPÓSIO BRASILEIRO E FORUM LATINO-AMERICANO DE GEOGRAFIA FÍSICA APLICADA, 7 e 1, 2002. Curitiba, Anais..., Paraná: UFPR, 2002, cd-rom.

LIMA, L. C.; ZANELLA, M. E. Análise dos paradigmas abordados nos livros didáticos do $6^{0}$ ano do ensino fundamental. In: SIMPÓSIO BRASILEIRO DE CLIMATOLOGIA GEOGRÁFICA, 9, 2010. Fortaleza. Anais..., Ceará: UFC, 2010, cd-rom.

LIMA, M. G. Climatologia: Reflexões sobre o seu ensino no curso de Graduação em Geografia. In: SIMPÓSIO BRASILEIRO DE CLIMATOLOGIA GEOGRÁFICA, 7, 2006. Rondonópolis. Anais..., Mato Grosso: UFMT, Z006, ed-rom. 
ISSN: 1980-055x (Impressa) 2237-8642 (Eletrônica)

MACHADO, G. Estação meteorológica: Uma alternativa para a melhoria do ensino de primeiro e segundo graus. Boletim Gaúcho de Geografia, Porto Alegre, n. 21, p. 151-153, 1996.

MAIA, D. C.; MAIA, A. C. N. A utilização dos ditos populares e da observação do tempo para a climatologia Escolar no Ensino Fundamental II. Revista Geotextos, Salvador, v. 6, n. 1, p. 51-71, 2010.

MAIA, D. C. Imagens de satélite meteorológico nas aulas de Geografia: Uma possibilidade didática. Revista Brasileira de Educação em Geografia. Uberlândia, v. 1, n. 2, p. 74-90, 2011.

MARIANO, Z. F.; SCOPEL, I.; FREITAS, V. V.; SOUSA, R. R. A utilização da estação meteorológica no ensino de climatologia para 4a, $5 a$ e $6 a$ séries do ensino fundamental. In: SIMPÓSIO BRASILEIRO DE CLIMATOlogiA GeOGRÁFICA, 5, 2002. Curitiba. Anais..., Paraná: UFPR, 2002, p. 1315-1322. cd-rom.

MEDEIROS, A. H. D.; HOLANDA, V. C. C. Geografia e Literatura de cordel: trilhando práticas e possibilidades em sala de aula. Caminhos da Geografia, Uberlândia, v. 9, n. 28, p. 134-145, 2008.

MISSIO, L. R.; SARTORI, M. G. B.; ALMEIDA, A. P. O clima nos livros didáticos de Geografia no ensino fundamental em Santa Maria-RS. In: SIMPÓSIO BRASILEIRO E CLIMATOLOGIA GEOGRÁFICA, 5, 2002. Curitiba. Anais..., Paraná: UFPR, 2002, cd-rom.

MORIN, E. A cabeça bem-feita: Repensar a reforma, reformar o pensamento. 7ed. Traduzido por: Eloá Jacobina. Rio de Janeiro: Bertrand Brasil, 2002, 128p.

MUNIZ, F. G. L.; CARACRISTI, I. A construção de materiais didáticos como técnica de aprendizagem da climatologia geográfica nas séries iniciais do ensino fundamental. In: SIMPÓSIO BRASILEIRO DE CLIMATOlOGiA GeOGRÁfiCA, 9, 2010. Fortaleza. Anais..., Ceará: UFC, 2010, cd-rom.

OLIVEIRA, L.; COLESANTI, M. T. O Ensino do clima através do livro didático no período de 189 a 1971. Boletim de Geografia Teorética, Rio Claro, n. 15. V. 29-30, p. 408-411, 1985.

OLIVEIRA, M. A geografia escolar: Reflexões sobre o processo didático do ensino. Revista Discente Expressões Geográficas, Florianópolis, n. 2, p. 10-24, jun/2006. Disponível: http://www.geograficas.cfh.ufsc.br/arquivo/ed02/artigo01.pdf. Acesso em 20 ago. 2012.

OITICICA, D. Céu de brigadeiro para a meteorologia. Jornal Gazeta Mercantil. Caderno Administração e Marketing. Rio de Janeiro, p. c-4, 8 de janeiro de 2002.

PINTO, P. H. P.; SOUZA, L. B. Análise dos conceitos de tempo e clima presentes em livros didáticos de Geografia do Ensino Fundamental. Brazilian Geographical Journal: Geosciences and Humanities research medium. Uberlândia, v. 2, n. 2, p. 369-380, 2011.

ROCHA, E. M. F.; GUAYCURU, V. M. S.; CRUZ, C. B. M. Aplicação de Imagens de Satélites como Recurso Didático no Ensino Fundamental e Médio para o estudo do Clima. In: SIMPÓSIO BRASILEIRO DE CLIMATOlOgiA GeOGRÁFICA, 5, 2002. Curitiba. Anais..., Paraná: UFPR, 2002, cd-rom, p. 1116-1124. ROSA, C. N.; LUCAR, H. D.; FOSA, M. I. T. Ditos populares meteorológicos na quarta colônia sob o olhar da comunicação social. In: SEMINARIO DE PESQUISA EM COMUNICAÇÃO, 4, 2004. Santa Maria. Anais..., Rio Grande do Sul: UFSM. http://www.ufsm.br/sipecom/anais/artigos/culturaidentidade/ROSA,\%20LUCAS\%20e\%20FOSSA.pdf. Acesso em 27 ago. 2012.

ROSA, R. Geotecnologias na geografia aplicada. Revista do Departamento de Geografia, São Paulo, n. $16, \quad$ p. $11-90, \quad 2005 . \quad$ Disponível http://www.geografia.fflch.usp.br/publicacoes/RDG/RDG_16/Roberto_Rosa.pdf. Acesso em 18 ago. 2012.

SANT'ANNA NETO, J. L. Por uma Climatologia Geográfica no Ensino de Graduação. in: SIMPÓSIO DE CLIMATOlogiA GEOGRÁFICA, 3, 1998. Salvador, Anais..., Bahia: UFBA, 1998, cd-rom.

SANT'ANNA NETO, J. A Climatologia geográfica no Brasil: Do que se tem produzido ao que se tem ensinado. in: SIMPÓSIO BRASILEIRO DE CLIMATOLOGIA GEOGRAFICA, 4., 2000, Rio de Janeiro, Anais..., Rio de Janeiro: UFRJ, 2000. cd-rom.

SANT'ANNA NETO, J. L. A climatologia geográfica em Brasil: De lo producido a lo enseñado. Investigaciones Geográficas, Alicante, n. 27, p. 227-236, 2002 . Disponível em: http://rua.ua.es/dspace/bitstream/10045/357/1/Sant\%27anna\%20Neto-

Climatologia\%20geografica.pdf. Acesso em 30 ago. 2002

SARTORI, M. G. B. A percepção do tempo e a cognição ambiental do homem rural do Rio Grande do Sul. In: SIMPÓSIO NACIONAL SOBRE GEOGRAFIA, PERCEPÇÃO E COGNIÇÃO DO MEIO AMBIENTE, 1, 2005. Londrina, Anais..., Paraná: 2005. UEL, Disponível em: http://geografiahumanista.files.wordpress.com/2009/11/maria_da_graca.pdf. Aceso em 27 ago. 2012. SAUSSEN, T. M. e MACHADO, C. B. A Geografia na sala de aula: informática, sensoriamento remoto e sistemas de informações geográficas - recursos didáticos para o estudo do espaço geográfico. In: JORNADA DE EDUCAÇÃO EM SENSORIAMENTO REMOTO NO ÂMBITO DO MERCOSUL, 4, 2004. São Leopoldo. Anais..., Rio Grande do Sul: Inpe, 2004, cd-rom.

SELLES, S. E.; FERREIRA, M. S. Influências nas representações sobre as estações do ano em livros didáticos de Ciências. Ciência e Educação, Bauru, v. 10, n. 1, p. 101-110, 2004. Disponível em: http://www.scielo.br/pdf/ciedu/v10n1/07.pdf. Acesso em 30 ago. 2012.

SILVA, F. G. CARNEIRO, C. D. R. As geotecnologias nos livros didáticos: uma análise para o ensino médio. SIMPÓSIO BRASILEIRO DE SENSORIAMENTO REMOTO, 15, 2011. Curitiba. Anais..., Paraná, 
ISSN: 1980-055x (Impressa) 2237-8642 (Eletrônica)

2011, p. 3295-3301. Disponível em: http://www.dsr.inpe.br/sbsr2011/files/p0311.pdf. Acesso em 18 ago. 2012.

SILVA FILHO. I. O mapa meteorológico do jornal nas aulas de Geografia. Disponível em: http://alb.com.br/arquivo-

morto/portal/5seminario/PDFs_titulos/O_MAPA_METEOROLOGICO_DO_JORNAL_NAS_AULAS.pdf. Acesso em 29 ago. 2012.

SILVA, F. F. S.; MARIANO, Z. F.; ROCHA, J. R. R.; SILVA, E. P. Ensino de climatologia utilizando os aparelhos da estação meteorológica. In: SIMPÓSIO BRASILEIRO DE CLIMATOLOGIA GEOGRÁFICA, 9, 2010. Fortaleza. Anais..., Ceará: UFC, 2010, cd-rom.

SIMIELLI, M. E. R. Cartografia no ensino fundamental e médio. In: CARLOS, A. F. A (org.). A Geografia na sala de aula. São Paulo: Contexto, 2001, p.92-108.

STEINKE, E. T.; STEINKE, V. A. Abordagem e aplicação da climatologia nos livros didáticos do Ensino médio. in: SIMPÓSIO DE CLIMATOLOGIA GEOGRÁFICA, 4, 2000. Rio de Janeiro, Anais..., Rio de Janeiro: UFRJ, 2000, cd-rom.

STEINKE, E. T.; GOMES, K. F. Instrumentação para o ensino de temas em climatologia com material multimídia. Revistas Didáticas Específicas, Madrid, n. 5, v. 1. 2011. Disponível em:

http://www.didacticasespecificas.com/files/download/5/articulos/44.pdf

STRANG, D. M. G. O clima visto como recurso natural. Boletim da Fundação brasileira para a conservação da natureza, Rio de Janeiro, v. 15, p. 40-49, 1980.

TARIFA, J. R. O ritmo e a prática do estudo dos climas de São Paulo (1970-2000). In: TARIFA, J. R.; AZEVEDO, T. R. (orgs.).: Os Climas na cidade de São Paulo: Teoria e prática.São Paulo: Pró-reitoria de Cultura e Extensão. Universidade de São Paulo. Laboratório de Climatologia. FFLCH. 2001, p.11-33, 199p.

TAKAHASHI, F. MEC vai propor a fusão de disciplinas do ensino médio. Jornal Folha de São Paulo. Caderno Cotidiano. São Paulo, 16 de agosto de 2012, p. C1.

TOMITA, L. M. S.; TOMITA, I. Y. Novos significados na aprendizagem: Linguagem do cotidiano no ensino de tempo e clima. In: SIMPÓSIO BRASILEIRO DE CLIMATOLOGIA GEOGRÁFICA, 9, 2010. Fortaleza. Anais..., Ceará: UFC, 2010, cd-rom.

TRISTÃO, M. As dimensões e os desafios da educação ambiental na sociedade do conhecimento. In: RUSHEINSKY, A. (org.). Educação ambiental: abordagens múltiplas. Porto Alegre: Artmed, p.169-173, 2002.

VERHAEGHE, J. C.; WOLFS, J. L.; SIMON, X.; COMPÉRE, D. Praticar a Epistemologia: Um manual de iniciação para professores e formadores. Traduzido por Nicolás Nymi Campanário. São Paulo: Edições Loyola, 2010, 241p.

VIANELLO, R. L.; ALVES, A. R. Meteorologia básica e aplicações. Viçosa: UFV, 2000, 449p.

ZUZA, E. S.; JESUS, A. C. No ar a meteorologia além da previsão do tempo: Um breve histórico das notícias climáticas no telejornalismo e perspectivas coma TV digital no Brasil. In: ENCONTRO NACIONAL DE HISTÓRIA DA MÍDIA, 7, 2009. Fortaleza. Disponível em: http://paginas.ufrgs.br/alcar/encontrosnacionais-1/7o-encontro-2009.pdf. Acesso em 17 ago. 2012.

ZUZA, E. S. O tempo como notícia e serviço na televisão digital: Proposta de produto para televisão universitária UNESP - HD. As relações no processo de montagem cinematográfica. $99 \mathrm{f}$. Dissertação (Mestrado em Televisão Digital: Informação e Conhecimento). Faculdade de Arquitetura, Artes e Comunicação da

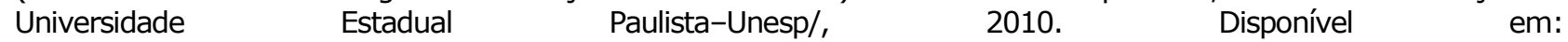
http://www.faac.unesp.br/posgraduacao/postvdigital/dissertacoes/pdfs/erikazuza.pdf. Acesso em 18 ago. 2012. 